Disponible en ligne : www.cahiersagricultures.fr

\title{
Innovation platforms and projects to support smallholder development - experiences from Sub-Saharan Africa
}

\author{
Janice Jiggins ${ }^{1, *}$, Dominique Hounkonnou ${ }^{2}$, Owuraku Sakyi-Dawson ${ }^{3}$, Dansou Kossou ${ }^{4}$, \\ Mamoudou Traoré $e^{5}$, Niels Röling ${ }^{6}$ and Arnold van Huis ${ }^{7}$ \\ ${ }^{1}$ Knowledge, Technology \& Innovation, Wageningen University, Wageningen, The Netherlands \\ 2 Connecting Development Partners International, Cotonou, Benin \\ 3 Department of Agricultural Extension, College of Agriculture and Consumer Studies, PO Box 68, University of Ghana, Legon, Ghana \\ ${ }^{4}$ Entomology \& Crop Protection, University of Abomey-Calavi, Abomey Calavi, Benin \\ 5 Institut Polytechnique Rural de Formation et de Recherche Appliqué (IPR/IFRA), Katibougou, Mali \\ ${ }^{6}$ Emeritus, Wageningen University, Wageningen, The Netherlands \\ ${ }^{7}$ Emeritus, Laboratory of Entomology, Wageningen University, Wageningen, The Netherlands
}

\begin{abstract}
Innovation as a policy goal, normative practice, and a conceptual framing of purposeful human activity, has received increasing attention. The question of what kinds of purposeful innovation might benefit smallholders in developing countries has been raised. This issue presents and analyses the work of Innovation Platforms (IPs) established by the COS-SIS (Convergence of Sciences-Strengthening Innovation Systems) programme in nine agro-enterprise domains in West Africa, drawing on Theory Guided Process Inquiry data recorded through 2011-end 2013. Six papers synthesise individual IP experiences, complemented by a cross-case analysis of external influences on the IPs and their responses, a reflection on how well the IPs in Mali dealt with local conflicts, and an analysis of how the work of the IPs in Ghana led to changes in university curricula and in the researching practices of three leading agricultural institutes. An analysis of thirteen case studies from Kenya, Benin, and South Africa supported by the JOLISAA (Joint learning in and about Innovation Systems in African Agriculture) programme, adds further insights. Five general lessons are drawn, expressed as propositions that can be further tested against others' experiences: (i) IPs can bring about significant socio-technical and institutional changes at a range of levels, and in a wide variety of agro-enterprise domains and contexts; (ii) the IPs are not isolated from nor independent of the networks of influence in which they are embedded; thus they cannot be treated as the sole causal agents of the changes accomplished; (iii) research that tracks the IPs' work and performance provides evidence that enables the members to learn from experience and adjust activities in the light of effects; (iv) there is no blueprint for what an IP is nor a recipe for the processes by which such changes are brought about; the form, activities, and changes co-evolve with whatever is happening in the wider context; (v) field-based diagnosis of opportunity, evidence-based information-sharing and experimental exploration of pathways of change establish the legitimacy and influence of IPs.
\end{abstract}

Keywords: institutional change / agro-enterprises / innovation platforms

\begin{abstract}
Résumé - Des projets et des Plateformes d'Innovation pour soutenir les petits producteurs quelques expériences en Afrique sub-saharienne. Ce numéro thématique présente et analyse les travaux et les résultats de Plateformes d'Innovation qui ont été mises en place et animées par le programme de recherche expérimental CoS-SIS (Convergence of Sciences-Strengthening Innovation Systems) dans neuf zones agricoles d'Afrique de l'Ouest entre 2011 et 2013. Six articles synthétisent les expériences locales de différentes plateformes d'innovation. Ils sont complétés par une analyse transversale des influences externes sur les plateformes d'innovation et des réponses de celles-ci, par une réflexion sur les réactions des plateformes d'innovation du Mali aux conflits locaux, et par une analyse des mécanismes par lesquels les plateformes d'innovation du Ghana ont influencé le contenu des enseignements universitaires et les programmes des instituts de recherche agronomique. Enfin, un article analysant les résultats du projet JOLISAA (Joint learning
\end{abstract}

\footnotetext{
* Corresponding author : janice.jiggins@inter.nl.net
} 
in and about Innovation Systems in African Agriculture) au Kenya, au Bénin, et en Afrique du Sud, apporte une vision complémentaire sur les mécanismes d'appui à l'innovation. On peut en tirer cinq leçons générales : i) les plateformes d'innovation peuvent générer des transformations sociotechniques et institutionnelles à différentes échelles et dans une grande variété de contextes; ii) ces plateformes d'innovation ne sont pas indépendantes de l'environnement dans lequel elles s'insèrent, et ne sont donc pas les seules causes des changements observés ; iii) le suivi de l'activité et des performances des plateformes d'innovation permet à leurs membres d'apprendre de leur expérience et d'ajuster leurs actions ; iv) il n'y a pas de recette universelle pour la mise en œuvre d'une plateforme d'innovation, les activités doivent évoluer avec le contexte et s'y adapter ; v) la légitimité et l'influence des plateformes d'innovation s'établissent sur la base d'un diagnostic de terrain, du partage de l'information et de l'expérimentation de différentes voies pour l'innovation.

Mots clés : transformations institutionnelles / entreprise agricole / plateformes d'innovation

\section{Innovation Platforms and projects to support smallholder development - experiences from Sub-Saharan Africa}

Knowledge is acquiring increasing commercial value. Scientific and technological capacities have become more widely distributed and harnessed to business and commercial interests as developing countries strive to become competitive market-led economies. Swan and Scarborough (2005) suggest that in these conditions innovation arises where collaborating groups and organisations meet to exploit knowledge for mutual profit (see also Faure et al., 2010). Research on innovation has drawn attention to the networking processes that emerge, both as spontaneous, self-organising responses to opportunity, and as deliberately designed and supported 'innovation systems' (Jiggins et al., 2014). The World Bank (2006) suggests that Innovation Platforms (IPs) are particularly well-suited to carry out the work of building new relationships and organisational arrangements, co-creating and integrating knowledge, and forming, and participating in and coordinating different kinds of networks in order to advance their members' purposes. Sanyang et al. (2014) provide evidence of how IPs can contribute to maize- and cassava-based value chain development in West and Central Africa. Recent studies urge a more nuanced and critical appreciation of the role of IPs in agricultural innovation (Jiggins et al., 2014). Moreover, participants in the Global Forum on Innovation in Africa warn that the IP label is now applied indiscriminately to a wide spectrum of effort. They argue for an emergent typology of IPs, from assemblages of district-level public agencies seeking to coordinate science-led technology change, to broader sets of actors interested in supporting the commercial development of target farmers and value chains, to those seeking to bring about the kinds of transformative changes described in this issue (Global Forum on Agricultural Research, 2015).

In order to capture this diversity, this issue begins with a critical cross-analysis of thirteen cases of agricultural innovation, selected from fifty-six published cases studies conducted in Benin, Kenya, and South Africa (Triomphe et al., 2016) The issue then focuses specifically on the role of IPs supported by the Convergence of Sciences-Strengthening Innovation Systems (COS-SIS) programme in six agro-enterprise domains in Benin, Mali and Ghana in West Africa. They analyse the processes by which the IPs established under the programme sought to bring about socio-technical and institutional change within their chosen domains, and reflect on the limitations and constraining factors, and some unanticipated spin-offs. Taken as a whole this issue seeks to offer policy-makers, practitioners and decision-makers, who are trying to unlock the potential of smallholder farming in Africa through agricultural innovation, robust answers to their key question of 'what works?' (Grindle, 2011). The findings and conclusions perhaps are relevant also elsewhere, complementing other recent literature on innovation in agriculture (Jiggins et al., 2016).

In the following sections we provide a brief introduction to the main elements of COS-SIS and a reflection on features of the programme that are not dealt with in the main articles but that we consider contributed significantly to the achievements and processes documented. We then draw out a number of general lessons based on the contributions to this issue, presented as a series of propositions that can be further tested against others' experiences.

\section{The COS-SIS programme}

The starting assumptions of the work recorded here can be summarised as follows: African smallholders themselves can be innovative and entrepreneurial; improving the productivity and profitability of their smallholdings is a sensible and practical way to attain broad-scale food security; and that smallholders need to be capacitated to compete in a globalised market. At the same time, it was acknowledged that formal agricultural research had had disappointing results, that an enabling environment (providing appropriate and timely services and infrastructures) often was lacking, and that the prevailing conditions exerted a 'pervasive bias' against smallholder farming in West Africa (Djurfeldt et al., 2005). The first phase programme, Convergence of Sciences (COS 1, 2001-2006), thus was supported by the Dutch Ministry of Development Cooperation in order to link university and research institute researchers to local 'innovation groups' in Ghana and Benin. The groups' members were varying mixes of local agricultural researchers, extension workers, staff of other service organisations, and men and women smallholder farmers. The focus was placed on the development through participatory research of locally relevant agro-technologies that provided substantial advantages in their context. Each group was further supported by a PhD student, recruited from the region. These students were jointly supervised by researchers at the University of Wageningen in The Netherlands, the University of Ghana, Legon, and the Université d'AbomeyCalavi in Benin (Hounkonnou et al., 2012). The immediate 
effects and local outcomes were positive, across a range of technologies and practices addressing farmers' problems in cocoa, oil palm, cereals, cotton and water, pest and soil management. Nonetheless, in each case the PhD students recorded significant institutional dilemmas that could not be resolved solely by means of technical innovations. Such dilemmas included, for instance, the various informal and formal ways that tenancy arrangements narrowed the opportunity space, as well as higher level organisational arrangements and networks of influence that in effect exploited smallholder farmers (Van Huis et al., 2007).

Moreover, when an additional PhD student from Wageningen University studied the longer-lasting effects and outcomes five years after the closure of the programme she found that a range of institutional constraints had blocked smallholders' further uptake of the beneficial socio-technologies and practices that had been developed and suppressed their own capacities for innovation (Sterk et al., 2013). Innovations developed through collaboration between local stakeholder groups and farmers under COS 1 survived the ending of programme support only when farmers themselves could control the conditions that enabled profitable use of the new technologies and practices. The starting hypothesis of the successor programme, COS-SIS (2008-end 2014), thus was that special effort was needed to transform or by-pass existing institutions, at a range of scales, so that smallholders can initiate, use and benefit from opportunities that strengthen their own livelihoods (Hounkonnou et al., 2012, 2016; Röling and Hounkonnou, 2014).

It had two over-arching aims. First, it sought to understand and test if Innovation Platforms (IPs) could bring about effective transformations in institutions, at a range of scales and levels, in ways that that benefited smallholders. Innovation Platforms were conceptualised both as innovations in existing institutional contexts and as the means by which institutional changes could be brought about. From the start, institutions were understood quite broadly, to include organisational arrangements, formal and customary law, relationships, practices, attitudes and norms. Secondly, as a research programme, COS-SIS sought to understand how innovation as a process of institutional change led by IPs actually occurs in diverse contexts over time (Hounkonnou et al., 2012).

COS-SIS operated as a partnership among five organisations: Wageningen University, The Netherlands; University of Ghana, Legon, Ghana; University of Abomey-Calavi, Benin; the Institut Polytechnique Rural de Formation et de Recherche Appliquée at Katibougou, Mali; and the Royal Tropical Institute, The Netherlands. The programme was funded by the Netherlands Ministry of Foreign Affairs, from 2008 to mid 2014 (COS-SIS, 2013). The main activities supported by the programme were:

- selection by national actors of key agricultural domains of significant importance to national development and smallholders' livelihoods;

- identification of the main socio-technical and institutional constraints experienced by smallholders in each domain on the basis of scoping studies (Adjei-Nsiah et al., 2013);

- diagnosis at a range of levels of the institutional reasons for these constraints, making visible the key actors, interests, networks and mechanisms that were maintaining them, and discovering potential 'entry points' for by-passing or transforming these (Jiggins, 2012);
- assembling and facilitating platforms of individuals of influence who were committed to engaging in the process of 'doing things differently and 'doing different things' (Nederlof and Pyburn, 2012);

- helping the IPs to experiment with new ways of working, organisational arrangements and relationships (Struik and Klerkx, 2014);

- providing well-documented, rigorous evidence of how institutions can be changed and processes of innovation can be supported (Jiggins et al., 2016);

- helping partners to influence university curricula, research institutes' programmes and capabilities, government policies and the structure of value chains, as well as agricultural industries, enterprises and services, based on the evidence generated;

- sharing the emerging information widely, throughout the life of the programme, and subjecting the accumulating experiences to critical review by diverse stakeholders, to foster the co-generation of knowledge and good practice (in eight regional and international conferences, 2009-mid2014).

The technical, socio-economic and institutional details of this collective effort by end 2014 had been published in 54 peer-reviewed articles, nine $\mathrm{PhD}$ theses, and two books. This issue attempts to draw out higher level lessons from these experiences.

The COS-SIS contributions to this issue draw on the data and information provided by preliminary scoping and diagnostic studies, PhD studies, the data and analyses recorded over four years, 2011-end 2013, within the framework of a Theory Guided Process Inquiry (TGPI), and on documentation of the action researching carried out with and by members of the IPs and PhD students (Jiggins et al., 2016). The lead authors acted as part-time facilitators of the IPs and as Research Associates (RAs). Together with the national coordinators, and members of a research support team (RAST) comprising individuals from universities and research institutes in the partner countries, the RAs analysed each of the IPs' experiences approximately every four months from the beginning of 2011 through to the end of 2013. The explanatory theories selected for this periodic examination of the data were framed in terms of 'power' and 'intervention'. The testing of the accumulating data against the espoused theories allows reasonable, evidence-based explanation of causal processes (Jiggins et al., 2016).

The main human resources supported by the programme can be classified under six headings:

- (i) provision by the Royal Tropical Institute, The Netherlands, of support to facilitation of the IPs (Nederlof and Pyburn, 2012);

- (ii) the part-time, post-doc Research Associates (RA), attached to each IP, who facilitated the work of the IPs and who documented the activities, processes, effects and outcomes of their work;

- (iii) PhD students, one for each domain, who carried out diagnostic studies (Jiggins, 2012) and studies of the institutional experiments carried out by the IPs (Struik and Klerkx, 2014);

- (iv) the RA Support Team (RAST), who supported the periodic reporting and analysis of the information and data 
assembled by the RAs, through 2011 to end 2013 (ii-iv are discussed in Röling and Hounkonnou, 2014).

Two further resources are highlighted in this Introduction:

- (v) the international programme coordination team, including the Regional Coordinator;

- (vi) the national coordinator, Programme Management Team (PMT) and Domain Advisory Committee for each country.

Based on the experiences of JOLISAA and COS-SIS, the following elements stand out from the various activities recorded. These are:

- the importance of involving a wide range of stakeholders in selecting the domain of interest, who can continue to support the innovation processes initiated 'on the ground';

- the necessity of both scoping studies that examine what the conditions actually are in the chosen contexts, and technical, social and institutional diagnostic studies in order to pinpoint the 'entry points' for action in each case;

- careful choice of the individuals, acting within their own capacities, in forming Innovation Platforms;

- facilitation of the IPs' work; technical and institutional experimentation and systematic joint learning, across a range of scales and administrative levels;

- collective, periodic (re)visioning of opportunities and review of progress.

The next section presents a number of general lessons and propositions that policy makers and investors in innovation might wish to take into account and test against their and others' experiences.

\section{Lessons and propositions}

The lessons and propositions sketched below provide a brief synthesis of what can be learned from the approaches and outcomes of the two programmes.

\subsection{It all takes time}

The COS-SIS international programme team consisted of a part-time programme manager (an entomologist), a part-time scientific adviser (a social scientist, both based at Wageningen University), and a regional coordinator, based in Benin. All three had had long careers living and working in various African countries and, prior to COS I, already had developed relationships of long-standing with key individuals and organisations in West Africa that were committed to smallholder development. The first two had stayed in touch with numerous former students who by then were well-placed in the region's National Agricultural Systems (NARs) and had access to the new scientific coordinator of agricultural research in the region, CORAF (the social scientist in fact had supervised the $\mathrm{PhD}$ of the regional coordinator). The Regional Coordinator, before moving back to his home country, Benin, had had a distinguished career in an international organisation supported by the EU that was based in Wageningen, and this had brought him into contact with the Dutch and French research communities as well as all the region's agricultural science organisations and university faculties, and the leading government officials dealing with agriculture.
The PhD supervisors based in the region and at Wageningen University had had similar experiences that enabled them to draw together the more easily as an interdisciplinary academic community of practice. Moreover, the partners in COS I were also the partners in COS-SIS (with the addition of the new partners in Mali), i.e. although there was a hiatus in securing funding between COS I and COS-SIS, the achievements were built on several intensive years of working together over 12 years or so. Triomphe et al. (2016), in this issue similarly stress that, on the basis of the experience of JOLISAA, effective innovation in the African context requires provision of continuing long term support to local effort as well as externally-initiated processes, beyond the artificial and protected environments of projects.

Thus our first proposition is that purposeful institutional innovation takes time and effort to create an extended history of mutually supportive collaboration.

\subsection{Leadership}

It is a truism to say that effective leaders create effective programmes but it begs the question of what effective might mean in the defined context. The COS-SIS experience points to the happenstance that the Regional Coordinator and his two Dutch colleagues (known as the core DNA of the programme, from the initials of their first names) turned out to have complementary temperaments and skills. No one predicted this in advance, nor were their respective roles carefully demarcated at the start of COS-SIS. Their relationship evolved in practice and in dialogue.

If we examine their leadership by means of the theory of group leadership elaborated in classic studies by Burke (1971) and Bates and Johnson (1972), with hindsight we might position the regional coordinator as the emotional leader, who was always ready to smooth feelings and discuss difficulties, to facilitate contacts and provide access, to encourage participants when things were tough and praise their efforts when the next small gain had been made. The programme coordinator would be positioned in this frame of reference as the task leader, negotiating budgets and ensuring that reporting was done in due order and on time, keeping track of the schedule of agreed activities, nudging performance towards stated goals and ensuring a sufficient coherence and coordination to maintain the programme's identity and impetus. More than that, he was always looking ahead, seeing how things were evolving and ensuring that financial resources and planned events would be available to support the emerging strategies as spaces for innovation opened up, i.e., he played a creative rather than merely directive or administrative role. The scientific adviser's role turned out to be that of guiding the intellectual conversation within the COS-SIS community and in the wider network of influence and champions. The main tools employed for this were by asking the difficult, probing questions; holding participants' accountable to COS-SIS' ambition and goals; and by insisting that the emerging experiences were publishable and ensuring that they were published.

We do not mean to suggest that leadership was the concern only of these three individuals. In fact, the programme could not have functioned unless all participants, as autonomous actors independent of the programme, voluntarily took on leadership responsibility in their own spheres of operation. In 
particular, we draw attention to the role of: (i) the members of the Domain Advisory Committees, comprising senior individuals of standing and influence within respectively Benin, Ghana and Mali, who met at least once a year. They acted within the domains as critics and champions of the approach (Struik and Klerkx, 2014; Van Paassen et al., 2014), bringing both their professional and networking capacities to bear on the evolving activities; (ii) the members of the PMTs who, exercising the authority of years of experience, seniority and wide repute, helped to resolve tensions, access the highest decision-making levels of society and government, and influence through discrete conversations both understanding and attitudes. They added considerably to the legitimacy of the IPs as a form of domain governance.

The exercise of leadership could perhaps be considered as a slowly evolving processes of interessement (a process analysed by Latour, 1996, for example).Vissoh et al. (2016), Sidibé et al., and Triomphe et al. (2016), in this issue, demonstrate how the determinants of innovation depend in part on strategic response to evolving relationships and in part on navigating changes in direction as the socio-political space for innovation (the dispositif) and contextual circumstances change. Thus our second proposition is that innovation programmes benefit from companionate leadership built on trust generated by shared action, and that combines creativity, distributed responsibility, and nurturing of inter-personal relationships that endure over time.

\subsection{Shared learning}

Beyond the sharing of information within the COS-SIS IPs, and among the organisations and individuals associated with their work, the programme invested to a considerable extent in sharing information and learning opportunities with wider stakeholder networks. Two types of regional co-learning workshops were organised: (i) through 2008-2012, involving the PhD students, RAs, the national coordinators, the chairmen of the Programme Management Committees, and programme management, i.e., for each of five workshops, about 30 persons were involved, at a cost per workshop of about Euro 40-50,000, and (ii) through 2009-2012, larger workshops that in addition involved all the $\mathrm{PhD}$ supervisors, i.e., for each of four workshops, about 70-80 persons were involved, at a cost per workshop of about Euro 70,000. By means of presentations by the $\mathrm{PhD}$ students and the RAs, followed by focussed discussions, the ongoing work and interim outcomes thus were subject to periodic peer review by and critique from both academic and practice communities. The deliberations were collated in published Proceedings and placed on the programme's open access website.

At the time the programme was initiated the international agricultural science community had spent many years debating, and attempting to practise, inter-disciplinary and trans-disciplinary research in agriculture - indeed, those involved had been among the pioneers in developing these researching practices. However, neither COS-SIS partners, nor the IPs' members, found such debates and advocacy of prescribed practices fruitful. They stated clearly at the first international symposium supported by COS-SIS that they preferred to focus on co-learning practices that facilitated their purposeful actions, and that seemed to fit in the socio- cultural contexts in which they were operating. The papers in this issue by Osei-Amponsah et al. (2016), Ouologuem et al., Soumano and Traoré, Adu-Acheampong et al., and Triomphe et al. (2016), in particular suggest there can be a considerable pay-off to the investment in this kind of shared learning, in terms of the catalytic effect on the institutions that govern domain activity. This potential is emphasised for instance also by Ison et al. (2000) and Hatchuel (2005). Lessons that might be drawn from the experiences reported in this issue are that an explicit prior, pre-analytic commitment to co-learning helps guide practice; co-learning favours the richness of diversity over expertise; co-learning can take many forms, and be supported across numerous scales and levels of interaction; and that co-learning is constituted both in joint practices and in objective evidence that is shared so as to inform practice.

This emphasis supports the understanding long established in the specialist literature - that 'knowledge' is constituted in the unique experiences and information accumulated and interpreted by individuals. Thus it cannot be 'transferred'. What can be communicated, in whatever form, is data, information and interpretations about what each of us knows. Science in this view is simply a specialised form of human activity that establishes objectively-verified claims about what is and can be known about the object of interest by careful application of self-aware procedural practices. The practise of science does not, however, encompass an individual's or group's entire life-world. Co-learning shifts the focus to mutual learning about how to understand the bases of other's experiences, and how to draw upon and communicate with others the data, information and interpretations generated by each person.

Our third proposition thus is that system innovation requires that scientific and other agencies involved in agricultural development for small farmers and agro-businesses invest in opportunities for co-learning, peer review and critique of their work by academics and practitioners in the domain of interest (and not just focus on science publications and publicity).

\subsection{Taking responsibility, embracing failure}

In the COS-SIS programme the scoping studies conducted in 2009 were used to make a preliminary selection of the agroenterprise domains. Throughout 2010, whilst diagnostic studies were being conducted in each of these domains, there was intensive practical, conceptual and theoretical discussion among COS-SIS participants about the meaning of core concepts such as 'innovation', 'institutional experiments,' 'systemic change', 'facilitation' and 'the role of the IPs'. At a meeting early in 2011 between the RAs, national coordinators and what was to become the RAST, the participants' questions crystallised around the following anxieties: were the IPs to be managed by the RAs, should the IPs be simply trying to implement objectives chosen by the programme, and were the RAs responsible for success or failure in achieving these? Were 'institutional experiments' actually another name for 'development projects'? The mood and practice began to turn around when it became accepted that within the frame of the programme's ambition, the IPs were responsible for defining 
their own agendas and setting their own successive objectives based on what they learned from action researching, and from the $\mathrm{PhD}$ and other studies. Further, it came to be understood that the RAs' roles were (a) to facilitate the maturing of the IPs' capacity to act, and (b) to monitor, document, assess and report the processes and outcomes that unfolded - a form of process tracing research that implied performance would not be judged in terms of prior criteria for the 'success' or 'failure' of the IPs. The IPs themselves came to be understood as institutional experiments, inserted into structures, organisational arrangements and relationships already existing in each context and that, among the mix of cases, variable performance would be a normal expectation. Further, it was accepted that performance drivers could originate in the context, beyond the IPs' or the programme's control (see further Essegbey et al., this issue). In fact in one case an IP as such was never established, partly because of the nature of the domain as a dry-land area of widespread poverty without a clear agro-enterprise focus, but also because the RA was transferred by his main employers to another part of the country. This case is not reported in this issue. We might also cite the case of Benin where the work of all three IPs was halted for about nine months, before, during and after Presidential elections.

Moreover, the kinds of institutional experiments that the IPs would carry out or support to effect change in the prevailing situation, in early 2011 still were unknown. It seemed likely that the IPs' emergent agendas in any case would be successively modified by experience and as new information was generated as they tried to do different things, and to do things differently i.e., a process of knowing through doing (Dupré, 1991; Albaladejo and Casabianca, 1997). Set backs and crises would be considered simply as insightful 'research data' and as opportunities for shared learning. Our fourth proposition thus is that innovation as an experimental process of change means (i) embracing 'failure', considered as an opportunity to learn, and (ii) placing responsibility where it belongs, close to the action, which can be located at any point of an administrative hierarchy or geographical space.

\subsection{Validity}

Innovation projects and programmes are challenged to provide evidence of internal and external validity. The papers in this issue offer a robust response to the challenges of establishing internal validity. The question of internal validity itself has two aspects: that which concerns the robustness of the outcomes of the interventions; and that which concerns researching how these outcomes might have been achieved. Robustness of outcome, as reported in the contributions to this issue, can be assessed in terms such as the quality of the IPs' memberships, where quality is constituted in the relevance of the membership, and their voluntary and persistent commitment to act; the IP members' praxis; the new pathways to change opened by their praxis; and the role of the IPs in conceptualising and bringing about purposeful change. With respect to the research that observed and documented how purposeful actions, co-evolving with their contexts, led to outcomes, we emphasis that TGPI was chosen explicitly to frame the research design of the COS-SIS programme (Jiggins et al., 2016), because TGPI is able to offer reasonable evidence of causalities in (a) contexts in which the actors, activities and purposes co-evolve over time, and (b) where the 'objects' of the interventions, and how these are perceived, are 'in flux', changed through action researching and information feedback.

The external validity of the claims made in the issue is not so well grounded, although the cross-analysis by Triomphe et al. (2016) offers a useful and robust procedure for establishing a reasonable degree of external validity. We further assume that by offering a common packet of interventions across diverse domains, and in three countries with different forms of domain governance and national cultures and histories, COS-SIS can claim that the external validity of Innovation Platforms, in the sense they are presented by the contributors to this issue and synthesised by Hounkonnou et al. (2016), to some extent has been put to the test. However, we can make no strong claims on this point. Our final proposition thus is that the external validity of the claim that purposeful interventions can catalyse or drive innovation outcomes that benefit smallholders is plausible but formally unproven.

\section{Overview of this issue}

The remaining papers of this issue first present a cross-case analysis (Triomphe et al., 2016) of published materials for 13 diverse 'innovation projects', from Kenya, South Africa and Benin. This paper offers both substantive insights into a range of innovation processes and interventions as well as an analytic procedure for comparing and contrasting innovation experiences. A series of country-based analyses follow that focus on the role of Innovation Platforms in catalysing institutional changes that allow smallholders to benefit from socio-technical opportunities, beginning with Vissoh et al. (2016) on an IP for improving the integrity of the oil palm seed system. Ouologuem et al. and Soumano and Traoré then examine the contributions of IPs in the Office du Niger in Mali, the former focussing on the integration of crop-livestock interests and the latter on improving water management and the position of tenants at the tertiary canal level. Traoré et al. (2017) then reflect on how well the Malian IPs dealt with deep-seated conflicts, an issue that the literature on innovation processes tends to ignore. The important point is made that while IPs can ameliorate or by-pass conflict situations, their efforts are insufficient to remove the fundamental reasons why such conflicts arise. Thereafter Adu-Acheampong et al. examine the contribution of a national-level IP made up of leading figures in the cocoa industry, Ghana's premier export-oriented agroindustry, while Adjei-Nsiah and Klerkx (2016) trace how a district-level IP assisted small scale women palm oil processors in Ghana to engage with the export market. Osei-Amponsah et al. (2016) round up the Ghanaian cases by analysing how the IPs, national coordinator, and the Domain and Programme Management Committees worked together to catalyse innovations in university curricula and the researching practices of three national agricultural research institutes in Ghana. That is, they show how strategic effort can build on the work of individual IPs to stimulate wider institutional innovation. The issue concludes with a cross-analysis of all the CoS-SIS IPs by Essegbey et al., based on a typology of external influences on agricultural domains and on the work of the IPs. The authors 
probe how well the IPs dealt with such influences, and the implications for how they operated and what they could achieve. This contribution links back to the first paper by stressing that IPs and other innovation efforts should not be seen as 'magic bullets', nor as 'all of a kind', but as diverse, creative responses to opportunity that co-evolve over time with their environment.

\section{Concluding remarks}

Overall the contributions to this issue highlight three key insights into purposeful innovation in smallholder agriculture in sub-Saharan Africa: the co-dependence of socio-technical and institutional innovation; the potential for strategically positioned IPs to bring about significant, far-reaching institutional transformation that opens wide-scale opportunity for small scale producers and processors; and the potential for actionresearching and shared learning to achieve cross-scale impact when these activities involve individuals who can influence their own organisations and who have access to the highest levels of official and governmental decision-making. The contributions further serve as a reminder that Innovation Platforms are not magic bullets, that they are not all of a kind, and nor are they the only way to promote innovations that transform smallholders' livelihoods and agro-business value chains.

Acknowledgements. The authors acknowledge with gratitude the numerous contributions of all COS I and CoS-SIS participants. The financial support of the Directorate General for International Cooperation of the Netherlands Ministry of Foreign Affairs is also gratefully acknowledged, as well as the interest shown by members of the Dutch Embassies in Ghana, Mali and Benin. We also would like to express our deep regret at the sudden passing away in 2014 of our dear friend and colleague Professor Owuraku Sakyi-Dawson, who contributed so much to the programme.

\section{References}

Adjei-Nsiah S, Adu-Acheampong R, Debrah K, Dembelé F, Soumano L, Ouologuem Bet al. 2013. Overcoming the bias against the small farm sector in Sub-Saharan Africa: scoping entry points for innovation platforms. Development in Practice 23(7): 857-871. Available from http://www.tandfonline.com/doi/full/10.1080/ 09614524.2013 .811220$.

Adjei-Nsiah S, Klerkx L. 2016. Innovation Platforms and institutional change: the case of small-scale palm oil processing in Ghana. Cah Agric, doi: 10.1051/cagri/2016046.

Adu-Acheampong R, Jiggins J, Tei-Quartey E, Karikari-Addo NM, Jonfia-Essien W, Quarshie E, et al. An innovation platform for institutional change in Ghana's cocoa sector. Cah Agric, submitted.

Albaladejo C, Casabianca F, eds. 1997. La recherche-action. Ambitions, pratiques, débats. Versailles: INRA Editions.

Bates CD, Johnson MM. 1972. Group leadership: a manual for group counselling leaders. Denver: Love Publishing.

Burke PJ. 1971. Task and social-emotional leadership role performance. Sociometry 34(1): 22-40.

COS-SIS. 2013. New pathways for innovation: creating conditions in which West African smallholders can capture opportunity. Wageningen: Wageningen University.
Djurfeldt G, Holmen H, Jirdström M, Larsson R, eds. 2005. The African food crisis: lessons from the Asian Green Revolution. Wallingford, UK: CAB International.

Dupré G, ed. 1991. Savoirs paysans et développement. Paris: KARTHALA/Éditions de l'ORSTOM.

Essegbey G, Sakyi-Dawson O, Kossou D, Ouologuem B, Dembelé F, Adu-Acheampong R, Jiggins J. External influences on agroenterprise innovation platforms in Benin, Ghana and Mali - options for effective responses. Cah Agric, submitted.

Faure G, Gasselin P, Triomphe B, Temple L, Hocdé H. 2010. Innover avec les acteurs du monde rural: la recherche-action en partenariat. Wageningen: CTA, Editions Quae, CTA, Presses agronomiques de Gembloux.

Global Forum on Agricultural Research (GFAR). 2015. Dr. Know \& Citizen Can: The futures of science and innovation platforms. Hosted Scientists Program, Abu Dhabi Food Control Authority, Abu Dhabi, March. Reported in GFAR News. Available from http:// www.gfar.net/news/dr-know-and-citizen-can-futures-science-andinnovation-platforms, consulted 10/12/2016.

Grindle M. 2011. Governance reform: the new analytics of next steps. Governance- An International Journal of Policy, Administration, and Institutions 24(3): 415-418.

Hatchuel A. 2005. Pour une épistémologie de l'action. L'expérience des sciences de gestion. Entre connaissance et organisation : l'activité collective. Paris: Éditions La Découverte.

Hounkonnou D, Kossou D, Kuyper T, Lewis C, Nederlof S, Röling $\mathrm{Net}$ al. 2012. An innovation systems approach to institutional change: smallholder development in West Africa. Agricultural Systems 108: 74-83.

Hounkonnou D, Brouwers J, van Huis A, Jiggins J, Kossou D, Röling Net al. 2016. Triggering regime change: a comparative analysis of the performance of innovation platforms that attempted to change the institutional context for nine agricultural domains in West Africa. Agricultural Systems. Available from http://dx.doi.org/ 70510.1016/j.agsy.2016.08.009.

Ison RL, High C, Blackmore CP, Cerf M. 2000. Theoretical frameworks for learning-based approaches to change in industrialised agricultures. In : Cerf M, Gibbon D, Hubert B, Ison R, Jiggins $\mathrm{J}$, Paine $\mathrm{M}$ et al., eds. Cow up a tree. knowing and learning for change in agriculture. Case studies from industrialised countries. Paris: INRA Éditions. 31-53

Jiggins J, ed. 2012. Special Issue. Diagnosing the scope for innovation: Linking smallholder practices and institutional context. NJAS 60-63: 1-121.

Jiggins J, Ison R, Röling N, eds. 2014. System innovation-towards sustainable agriculture. Special Issue. Outlook on Agriculture 43(3): 145-223.

Jiggins J, Essegbey G, Klerkx L, van Paassen A, Pyburn R, Tossou R. 2016. The Use of Research in and Across Nine Agro-Enterprise Domains. The Experience of the Convergence of SciencesStrengthening Innovation Systems Programme in Benin, Ghana and Mali. In : Francis J, Mytalka L, Van Huis A, Röling N, eds. Innovation Systems: Towards effective strategies in support of smallholder farmers. Proceedings of an Expert Consultation organised by COS-SIS and CTA, held at CTA, Wageningen, The Netherlands, February 2013.Wageningen, COS-SIS/CTA, in press.

Latour B. 1996. Aramis or the love of technology. Cambridge, MA, Harvard University Press (Originally published 1993 as Aramis, ou l'amour des techniques). Paris: Éditions La Découverte.

Nederlof S, Pyburn R, eds. 2012. One finger cannot lift a rock. Facilitating innovation platforms to trigger institutional change in West Africa. Amsterdam: KIT Publishers. 
Osei-Amponsah C, Sakyi-Dawson O, Adjei-Nsiah S, Adu-Acheampong R, Essegbey G, Quarmine W. 2016. Embedding research for innovation to meet societal needs in national research systems: experiences from Ghana. Cah Agric, doi: 10.1051/cagri/2016047.

Ouologuem B, van Paassen A, Traoré M, Jiggins J. Résoudre les conflits par le changement institutionnel. Rôle d'une plateforme d'innovation pour l'intégration agriculture-élevage à l'Office du Niger (Mali). Cah Agric, soumis.

Röling N, Hounkonnou D. 2014. Innovation Systems and Institutional Change. Paper presented at CTA conference on Innovations in Agricultural Extension and Advisory Services: Linking Knowledge to Policy and Action for Food and Livelihoods, Nairobi, November 15-18 2011, Proceedings. Available from http://extension.cta.int/ Read at 29.12.2011.

Sanyang, S, Pyburn R, Mur R, Audet-Bélanger G, eds. 2014. Against the grain ad to the roots. Maize and Cassava Innovation Platforms in West and Central Africa. CORAF/WECARDDakar and Amsterdam: KIT Publishers.

Sidibé A, Vellema S, Dembelé F, Traoré M, Kuyper TW. Analyse d'une plateforme d'innovation dans la filière karité au Mali. Cah Agric, soumis.

Soumano L, Traoré M. Action research to Improve Water Management in the Office du Niger, Mali. Cah Agric, submitted.

Sterk B, Kobina AC, Gogan AC, Sakyi-Dawson O, Kossou D. 2013. Five years after: the impact of a participatory technology development programme as perceived by smallholders in Benin and Ghana. International Journal of Agricultural Education and Extension 19(4): 361-379.

Struik P, Klerkx L, eds. 2014. Institutional change towards sustainable agriculture in West Africa. Special Issue. International Journal of Agricultural Sustainability 12(3): 201-382.

Swan J, Scarborough H. 2005. The politics of networked innovation. Human Relations 58: 913-943.

Triomphe B, Floquet A, Letty B, Kamau G, Almekinders C, WatersBayer A. 2016. Mieux évaluer et accompagner l'innovation agricole en Afrique. Leçons d'une analyse transversale de 13 cas d'études. Cah Agric, doi: 10.1051/cagri/2016050.

Van Huis A, Jiggins J, Kossou D, Leeuwis C, Röling N, SakyiDawson Oet al., eds. 2007. Research researched: Can convergence of agricultural sciences support innovation by resource-poor farmers in Benin and Ghana? International Journal of Agricultural Sustainability 52/30: 89-264.

Van Paassen A, Klerkx L, Adu-Acheampong R, Adjei-Nsiah S, Zannoue E. 2014. Agricultural Innovation Platforms in West Africa: does strategic institutional entrepreneurship unfold in different value chain contexts? Outlook on Agriculture 43(3): 193-200.

Vissoh PV, Tossou RC, Akpo E, Kossou D, Jiggins J. 2016. Innovating a system for producing and distributing hybrid oil palm seedlings to smallholder farmers in Benin. Cah Agric 25(6).

World Bank. 2006. Enhancing Agricultural Innovation: How to Go Beyond the Strengthening of Research Systems. Washington DC: World Bank.

Cite this article as: Jiggins J, Hounkonnou D, Sakyi-Dawson O, Kossou D, Traoré M, Röling N, van Huis A. 2016. Innovation platforms and projects to support smallholder development - experiences from Sub-Saharan Africa. Cah. Agric. 25: 64002. 